\title{
Role of music in operating room
}

Volume 7 Issue 5 - 2017

\section{Introduction}

The therapeutic effects of music on the patients during and after surgery have been reported which reduces the anxiety and pain levels. ${ }^{1-3}$ A very few studies have demonstrated the effect of music on the operating room (OR) staff. ${ }^{4-6}$ Peretti measured galvanic skin responses and reported that music had a calming effect during a stressful task . ${ }^{7}$ Music has also been associated positively with performance on stressful tasks. Ethical and practical concerns limit the use of a true field experiment to test the hypothesis that music reduces surgeon stress and enhances surgical performance. However the study by Allen et al demonstrated clearly that surgeon-selected music was associated with reduced autonomic reactivity and improved performance of a stressful nonsurgical laboratory task. ${ }^{5}$ Some surgeons claim to perform better with music, but others fear it has a potentially disturbing influence. The study by Miskovic et al., ${ }^{8}$ showed that music in OR may have a distracting effect on novice surgeon performing new tasks and surgical trainees should consider switching off music during teaching procedures. ${ }^{8}$ However the type of music and volume used is an interesting factor. The following study was conducted among the plastic surgeons to know their preferences about the music during surgery.

\section{Materials and methods}

A questionnaire (Figure 1) was designed and distributed among the 200 plastic surgeons selected randomly who were the members of Pakistan Association of Plastic Surgeons (PAPS), IPRAS, ASAPS and Australian Society of Plastic Surgeons (ASPS). The surgeons were divided into two groups. Group A comprised of the plastic surgeons from the Asian subcontinent. Group B consisted of plastic surgeons living in Australian, American and European nations. From group A, 100 plastic surgeons were chosen randomly and 100 plastic surgeons. The surgeons were asked to return the questionnaire within 60days.

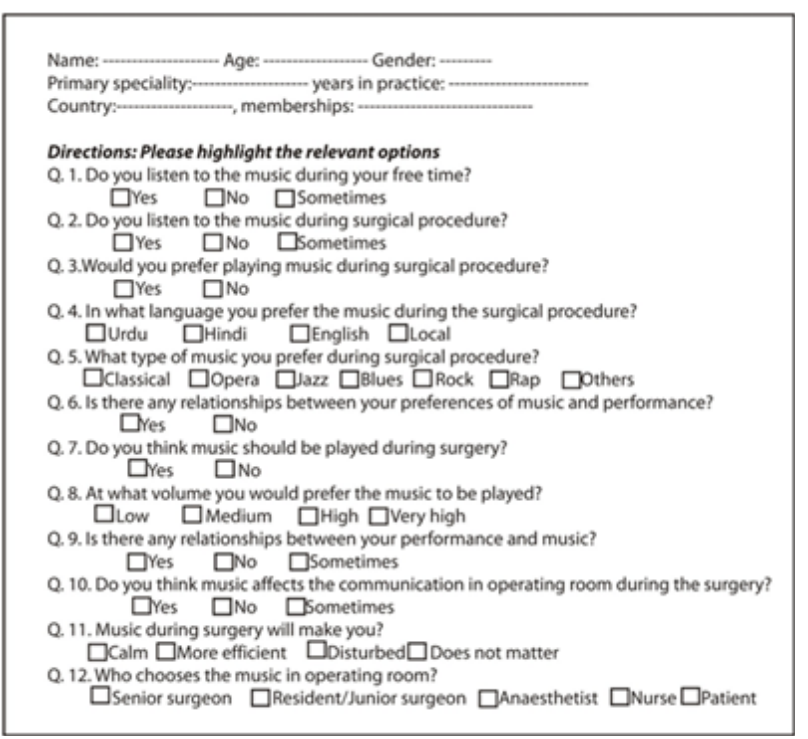

Figure I Questionnaire.

\section{Muhammad Ahmad \\ Plastic and Hair Restorative Surgeon, Pakistan}

Correspondence: Muhammad Ahmad, Plastic and Hair Restorative Surgeon, Hair Transplant Institute Aesthetic Plastic Surgery, H. I-B, Main Kohistan Road, F-8/3, Islamabad, Pakistan, Tel +92-300-5239465, Email plasticsurgeon999@yahoo.com

Received: March 03, 2017 | Published: April 13, 2017

\section{Results}

The answers of all the plastic surgeons from each group were analyzed.

i. Music in free time: About $97 \%$ of group A and $99 \%$ of group B listen to the music in their free time.

ii. Music during surgical operation:Sixty seven percent of group $\mathrm{A}$ and $81 \%$ of group $\mathrm{b}$ listen to music during surgical operation whether local or general anaesthesia.

iii. Language:Eighty nine percent of group A and $98 \%$ of group B listen to English music.

iv. Type of music: Twenty nine of group A and $35 \%$ of group B listen to classical music whereas only very few (4\% in group A and $2 \%$ in group B) listen to high pitched music (Table 1).

Table I Type of Music

\begin{tabular}{llllllll}
\hline Group & Classical & Opera & Jazz & Blues & Rock & Rap & Others \\
\hline Group A & 29 & 24 & 41 & 2 & I & 2 & I \\
Group B & 35 & 29 & 31 & 3 & I & I & - \\
\hline
\end{tabular}

v. Preference of music: About one tenth of the surgeons of group A had a specific preference to play the music in OR whereas only $2 \%$ in group B had it.

vi. Music during surgery: Eighty one percent of the surgeons (group A) and $93 \%$ (group B) wished the music to be played during the surgery.

vii. Volume of music: Majority of the surgeons (71\% in group A and $84 \%$ in group B) liked the music to be played in low volumes (Table 2). 
Table 2 Volume of Music

\begin{tabular}{lllll}
\hline Group & Low & Medium & High & Very High \\
\hline A & 71 & 29 & - & - \\
B & 84 & 16 & - & - \\
\hline
\end{tabular}

viii. Performances and music: Only few surgeons (14\% in group A and $21 \%$ in group B) thought to have worked better while the music being played during the surgery.

ix. Effect on communication: Majority of the surgeons in both the groups had the views that playing music in OR did not affect the communications with the OR staff (Figure 2).

$x$. Personal feelings: Most of the surgeons in both the groups felt calm while performing the surgeries with the music playing in OR (Table 3).

Table 3 Who chooses the musi

\begin{tabular}{llllll}
\hline Group & Surgeon & $\begin{array}{l}\text { Resident/ } \\
\text { Junior } \\
\text { Surgeon }\end{array}$ & Anesthetist & Nurse & Patient \\
\hline A & 40 & 38 & 12 & 9 & 1 \\
B & 38 & 35 & 15 & 8 & 4 \\
\hline
\end{tabular}

Person choosing the music: In majority of the cases, the senior surgeon chose the music (Figure 3).

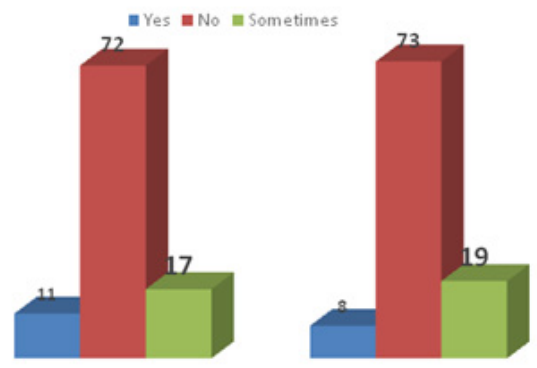

Figure 2 Effect on Communication.
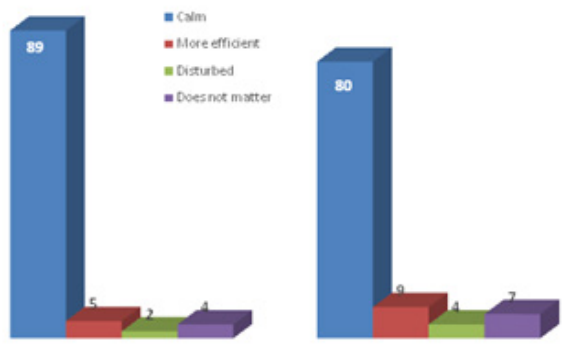

Figure 3 Surgeon's feelings.

\section{Discussion}

Working in OR is somewhat unique in comparison with working in other professional settings. It is probably the most stressful environment and surgeons being the sole captain of the ship, is under stress. The beneficial anatomic effects of music have been mentioned in the literature. ${ }^{4-6}$ The music in OR plays a double role. On one hand, it alleviates the anxiety of the patients about the surgical procedure and OR environment. On the other hand, it relieves the stressful conditions of surgical and OR staff. The studies by Arsalan et al., and Tabarro et al. ${ }^{4}$ showed that the patients undergoing surgery were able to manage the pre-operative anxiety more readily than those not listening to the music in pre-op time.$^{1,4}$ Similarly, the study by Allan et al also indicated the improved performance in the surgeons. ${ }^{5}$

In the present study, we attempted to analyze the overall general views of the plastic surgeons about music in the OR. A similar study was carried out by Ullan et al., ${ }^{6}$ Anxiolytic effects of music on patients before, during and after surgery have been long recognized and are well establishes. ${ }^{9,10}$ The sources in operating room like sucker, anaesthetic monitoring machines, dropping of the instruments emit the noises of $80-108 \mathrm{~dB} .{ }^{11,12}$ These sounds could be very uncomfortable to OR staff especially to the surgeon. An ambient music being played in OR helps to reduce or mask the annoying sounds. Moreover, the speed and accuracy of the surgeon has been shown to enhance by the music especially if the music is familiar to the surgeon. ${ }^{5,13,14}$ About $74 \%$ of the surgeons in the present study listened to the music which is higher than those in Ullan et al., ${ }^{6}$ In the current study, only $17.4 \%$ of the surgeons thought they worked better while music was playing which is in contrast to the observation noted in other studies.

It is shown in studies that listening to the music improved the speed and quality of wound closure. ${ }^{15}$ On the other hand loud music can impair the communication and cause distraction resulting in increased incidence of surgical site infections. ${ }^{16}$ A survey in 1997 reported that $26 \%$ anesthesiologists found it distracting. ${ }^{12,17}$

\section{Conclusion}

The music can be employed as an adjunct to obtain physical and emotional. The slow music being played in the operating room can alleviate the anxiety and has pleasing effect on surgeon, staff and patient.

\section{Acknowledgements}

None.

\section{Conflicts of interest}

Author declares there are no conflicts of interest.

\section{Funding}

None.

\section{References}

1. Arslan S, Ozer N, Ozyurt F. Effect of music on preoperative anxiety in men undergoing urogenital surgery. Austl J Adv Nursing. 2008;26(2):46-54.

2. Byers JF, Smyth KA. Effect of a music intervention on noise annoyance heartrate and blood pressure in cardiac surgery patients. Am J Crit Care. 1997;6(3):183-191.

3. Fratianne RB, Prensner JD, Huston HJ, et al. The effect of music-based imagery and musical alternate engagement on the burn debridemnt process. J Burn Care Rehabil. 2001;22(1):47-53.

4. Tabarro CS, de Campos LB, Galli NO, et al. Effect of the music in labor and newborn. Rev Esc Enferm USP. 2010; 44(2):441-448.

5. Allen K, Blascovic J. Effects of music on cardiovascular reactivity among surgeons. JAMA. 1994;272(11):882-884.

6. Ullmann Y, Foder L, Schwarzberg I, Carmi N, Ullmann A, et al. (2006) The sounds of music in the operating room. Injury 39(5): 592-597.

7. Peretti PO, Swenson E. Effects of music on anxiety as determined by physiological skin responses. J Res Music Educ. 1974;22(4):278-281.

8. Miskovic D, Rosenthal R, Zingg U, et al. Randomized controlled trait investigating the effect of music on the virtual reality laparoscopic learning performance of novice surgeons. Surg Endosc. 2008; 22(11):2416-2420. 
9. Makama JG, Ameh EA, Eguma SA. Music in the operating theatre: opinions of staff and patients of a Nigerian teaching hospital. African Health Sci. 2010;10(4):386-389.

10. Whipple B, Glynn NJ. Quantification of effects of listening to music as a noninvasive method of pain control. Scholarly inquiry of Nursing Practice. 1992;6(1):43-62.

11. Liu TS. Patients' perception of sound levels in surgical suite. $J$ Clin Anesthe. 2000;12(4):298-302.

12. Fontaine CW, Shwalm ND. Effects of familiarity of music on vigilant performance. Percept Mot Skills. 1979;49(1):71-74.

13. Landreth JF, Landrith HF. Effects of music on physiological response. $J$ research music Edu. 1974;22(1):4-12.
14. Rausher RH, Shaw GL, Ky KN. Music and spatial task performance. Nature. 1993;365:611.

15. Lies SR, Zhang AY. Prospective randomized study of the effect of music on the efficiency of surgical closures. Aesthet Surg J. 2015;35(7):858-863.

16. Kurmann A, Peter M, Tschan F, et al. Adverse effect of noise in the operating theatre on surgical-site infection. $\mathrm{Br} J \mathrm{Surg}$. 2011;98(7):1021-1319.

17. Hawksworth C, Asbury AJ, Millar K. Music in theatre: not so harmonious: a survey of attitudes to music played in the operating theatre. Anesthesia. 1997;52(1):79-83. 